\title{
Práticas tradicionais e conhecimentos associados ao uso e maNejo da AGrobiodiversidade nas Comunidades ruRais Saloba Grande e Novo Oriente, Porto Estrela, MT, Brasil
}

\author{
Luana Auxiliadora Apoitia Ourives ${ }^{1 *}$, Maria Antonia Carniello ${ }^{2}$
}

\author{
${ }^{1}$ Secretaria de Educação do Estado de Mato Grosso. Escola Estadual Prof Ana Maria das Graças de Souza Noronha. Rua dos Monteiro, s/n, Jardim \\ Padre Paulo, Cáceres, Mato Grosso, Brasil. CEP: 78200-000. \\ ${ }^{2}$ Faculdade de Ciências Agrárias e Biológicas, Departamento de Ciências Biológicas, Campus universitário Jane Vanini. Universidade do Estado de Mato \\ Grosso (UNEMAT), Av. São João, s/n-Cavalhada, Cáceres, Mato Grosso, Brasil. CEP: 78200-000. \\ *Autorpara correspondência: luanapoitia@hotmail.com
}

Recebido em 05 de julho de 2017. Aceito em 05 de março de 2018. Publicado em 21 de abril de 2018.

\begin{abstract}
Resumo - Espaços de cultivo como quintais, chácaras e roças representam alternativa para a subsistência alimentar de populações rurais no sudoeste do Estado de Mato de Mato Grosso. O objetivo deste estudo foi registrar o conhecimento local associado ao uso e manejo da agrobiodiversidade produzida em roças de unidades rurais do entorno da Estação Ecológica da Serra das Araras. Esta pesquisa foi aprovada pelo Comitê de Ética em Pesquisa - parecer no 1.404 .395 e desenvolvida

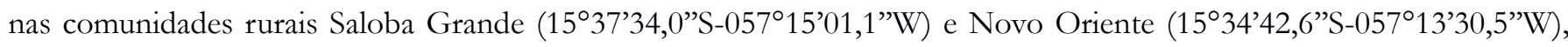
em Porto Estrela, MT. Participaram desta pesquisa, 4 famílias. Utilizou-se a técnica bola de neve para a coleta dos dados e a aplicação de métodos com abordagens qualitativas e quantitativas, observação participante e amostragem de vegetação. Foram obtidas 22 espécies vegetais (cultivadas ou espontâneas) com maiores indicações de uso para Attalea speciosa Mart. ex Spreng. (Babaçú) (6) e Mangifera indica L. (Manga) (5). O manejo de roças está diminuindo na região, fator que recai sobre o etnoconhecimento associado a população local, que ao não ser fortalecido por meio do seu modo de vida pode ser perdido ao longo tempo.
\end{abstract}

Palavras-chave: Roças; Quintais; Etnoconhecimento.

Traditional PRACTICES AND KNOWLEDGE ASSOCIATED WITH THE USE AND MANAGEMENT OF AGROBIODIVERSity IN RURAL communities of Saloba Grande and Novo Oriente, Porto Estrela, MT, Brazil

ABstraCt - Areas of cultivation such as home gardens, farmsteads and farms typify alternatives for the food subsistence of rural populations in the Southwest of the state of Mato Grosso. The aim of this study was to register the local knowledge associated with the use and management of agrobiodiversity in rural units near the Serra das Araras ecological station. This research was approved by the Ethics Committee - statement n. 1.404 .395 and took place in the rural communities

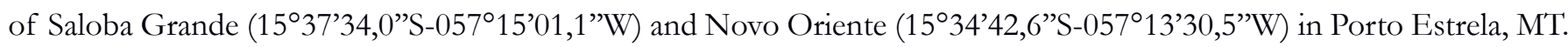
Four families took part in this research. In order to collect data, we used the snowball sampling, quantitative and qualitative methodological approaches, participant observation and vegetation sampling. Twenty-two species of plants were obtained (spontaneous or cultivated) with higher indications of use of Attalea speciosa Mart. ex Spreng. (Babaçú) (6) and Mangifera indica L. (Manga) (5). The management of farmsteads is decreasing in the region, which affects the local populations' traditional knowledge. If it is not strengthened by their lifestyle, it might get lost over time.

Keywords: FARMS; Home GaRdENS, TRADITIONAL KNOWLEDGE.

Prácticas tRadicionales y CONOCIMIENTOS ASOCIADOS AL USO Y MANEJO DE LA AGROBIODIVERSIDAD EN LAS COMUNIDADES 


\section{rurales Saloba Grande y Novo Oriente, Porto Estrela, MT, Brasil}

RESUmen - Espacios de cultivo como huertos, chacras y rozas representan una alternativa para la subsistencia alimentaria de poblaciones rurales en el suroeste del Estado de Mato Grosso. El objetivo de este estudio fue registrar el conocimiento local asociado al uso y manejo de la agrobiodiversidad producida en rozas de unidades rurales del entorno de la Estación Ecológica de la Serra das Araras. Esta investigación fue aprobada por el Comité de Ética en Investigación - dictamen $\mathrm{n}^{\circ} 1.404 .395$ y desarrollada en las comunidades rurales Saloba Grande $\left(15^{\circ} 37^{\prime} 34,0{ }^{\prime \prime S}-057^{\circ} 15^{\prime} 01,1\right.$ ”'O) y Novo Oriente

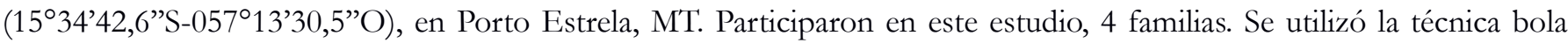
de nieve para la recolección de datos y la aplicación de métodos con abordajes cualitativos y cuantitativos, observación participante y muestreo de vegetación. Fueron obtenidas 22 especies vegetales (cultivadas o espontáneas) con mayores indicaciones de uso para Attalea speciosa Mart. Ex Spreng. (Babaçú) (6) y Mangifera indica L. (Manga) (5). El manejo de las rozas está disminuyendo en la región, factor que recae sobre el etnoconocimiento asociado a la población local, que al no ser fortalecido por medio de su modo de vida puede perderse a lo largo del tiempo.

Palabras clave: Rozas; Huertos; Etnoconocimiento.

\section{INTRODUÇão}

Em todo o mundo grande parte da agrobiodiversidade prospera em agroecossistemas complexos que são mais frequentemente geridos por pequenos agricultores (Galluzzi et al. 2010).

Para garantir sua subsistência alimentar, por milhares de anos, pequenos agricultores, principalmente das zonas tropicais, têm manejado seus campos e contribuído para a conservação da diversidade vegetal (Amorozo 2013).

Desde os tempos coloniais os pequenos agricultores brasileiros utilizam técnicas autóctones de produção agrícola, as quais são repassadas verticalmente (Oliveira 2012), e também horizontalmente nas relações de compadrio e vizinhança entre as famílias (Amorozo 2013).

No entanto, as últimas décadas foram marcadas por intensas transformações no meio rural do país. Ocorreram substituições de instrumentos de trabalho e insumos tradicionais por inovações que "modernizaram" a agricultura. $\mathrm{O}$ rápido crescimento dessas mudanças provocou maior dependência das unidades familiares aos produtos de mercado (Grisa 2007).

Em 1986, Posey afirmou que o grande dilema do desenvolvimento se constituía no fato dos camponeses e pequenos agricultores não terem condições de assumir os custos dos maquinários e insumos agrícolas. Como consequência surge um sistema incapaz de manter-se diante do desmatamento em grande escala e a monocultura, e o aparecimento de uma série de situações, "revoluções verdes", sem se considerar as consequências sociais.

Os agricultores familiares detêm experiências, adquiridas durante muito tempo no trato com a terra, nos conhecimentos transferidos de geração em geração e em suas observações nas relações da natureza que se aplica desde a escolha das sementes para o plantio até a colheita.

Para Rigonato e Almeida (2004), o conhecimento, o cotidiano, o modo de vida de determinadas populações que ainda mantém práticas tradicionais podem contribuir com mecanismos sociais e culturais de conservação da biodiversidade do bioma Cerrado e se constituir como instrumento indispensável para a manutenção dos povos e suas respectivas culturas.

O entorno da Estação Ecológica da Serra das Araras (EESA), especialmente na porção Oeste de sua sede é ocupado por populações de pequenos agricultores que manejam suas áreas firmado em um sistema agrícola 
de pequena escala e apresentam relevante importância para a subsistência das famílias e por fazendas cuja base da economia está centrada na atividade pecuária extensiva em larga escala. Neste sentido o objetivo deste estudo foi registrar o conhecimento local associado ao uso e manejo da agrobiodiversidade produzida em roças de unidades rurais do entorno da Estação Ecológica da Serra das Araras nas comunidades Saloba Grande e Novo Oriente.

O registro de conhecimentos locais associados às práticas tradicionais agrícolas ainda mantidas por pequenos agricultores, geram dados que podem fornecer suporte para entender como a população reconhece, cultiva, utiliza e se relaciona com as plantas.

\section{Material e MÉtodos}

Esta pesquisa foi realizada em pequenas unidades rurais localizadas ao redor da Estação Ecológica da Serra das Araras que compreendem as comunidades rurais Saloba Grande e Novo Oriente, com pontos de referência $\left(15^{\circ} 37^{\prime} 34,0^{\prime \prime S}-057^{\circ} 15^{\prime} 01,1^{\prime \prime} \mathrm{W}\right)$ e (15³4’42,6”; 057¹3’30,5”W), respectivamente, ambas localizadas no município de Porto Estrela, região Sudoeste de Mato Grosso (Figura 1).

Figura 1 - Localização das comunidades rurais Saloba Grande e Novo Oriente no entorno da Estação Ecológica da Serra das Araras, município de Porto Estrela. Legenda: Sb: córrego Saloba Grande; 3Ri: córrego Três Ribeirões; Cch: córrego cachoerinha; Jq: córrego Jauquara.
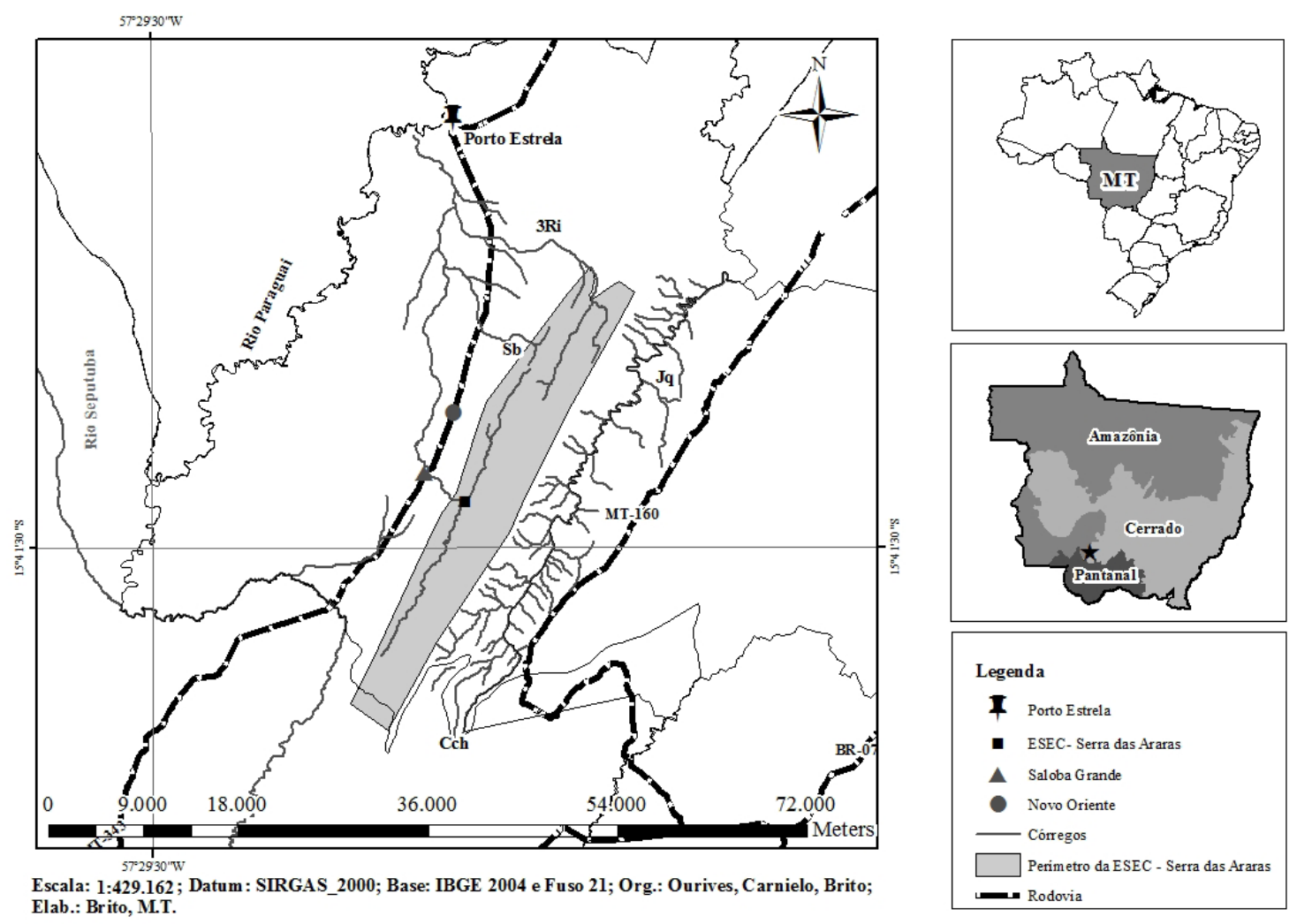

Segundo o IBGE (2010) Porto Estrela é constituído por 3.649 habitantes, 1.466 residentes na zona urbana e 2.183 na zona rural. Sua economia inclui atividades de pecuária e agricultura destacando-se as culturas as de algodão, milho, feijão e arroz. 
A região é conhecida localmente como morraria, denominação local utilizada para nomear uma extensa região delineada por serras e vales sob vegetação de Cerrado, reconhecida nos estudos geomorfológicos como a unidade de relevo Província Serrana (Aguiar 2007).

Saloba Grande dista $5 \mathrm{~km}$ da sede da estação, enquanto que Novo Oriente possui unidades rurais localizadas a menos de $3 \mathrm{~km}$ em linha reta dos limites da EESA. É constituída por cerca de 35 famílias. Suas residências são agrupadas as margens da rodovia MT 343 que formam uma vila circundada por pequenas unidades rurais, sendo caracterizada como um bairro estabelecido no meio rural.

Novo Oriente é composta por aproximadamente 20 famílias. Possui unidades rurais localizadas a menos de $3 \mathrm{~km}$ em linha reta dos limites da EESA (MMA 2015) e a 4 km de Saloba Grande.

A economia local de ambas as comunidades baseia-se na comercialização de produtos agrícolas oriundos do excedente produzido nos quintais, chácaras e pequenas roças, pecuária de corte e leiteira, em pequena escala para os agricultores locais e grande escala para os imigrantes proprietários de grandes áreas.

A vegetação local apresenta cinco diferentes tipos de formações: mata ciliar, mata semi-decídua, cerradão, cerrado sentido restrito e parque cerrado (Valadão 2012), definidas e caracterizadas conforme Ribeiro e Walter Filho (2008).

Este estudo foi desenvolvido entre Setembro, 2015 e Dezembro, 2016. Foram utilizadas abordagens qualitativas e quantitativas. Os instrumentos para a coleta dos dados consistiram em entrevistas estruturadas e semiestruturadas com participantes da pesquisa em suas residências, listas-livres, observação participante e respectivos registros em diário de campo, registros fotográficos, gravações de áudio e vídeo e amostragem da vegetação.

Para cada contato com os entrevistados utilizou-se a técnica bola de neve (Goodman 1961) iniciada com um esperto local, que indicou os próximos participantes, e assim sucessivamente. Dentre as 28 famílias agricultoras indicadas, participaram deste estudo 4 famílias que ainda empreendem práticas tradicionais de manejo de roças.

Para coleta dos dados foram realizadas oito missões de campo com permanência na comunidade entre três e sete dias consecutivos.

As informações sobre a flora conhecida e utilizada no cotidiano das famílias, bem como a origem do acervo botânico, a apropriação e a transmissão do conhecimento foram coletadas segundo as orientações metodológicas de Alexíades (1996), Bernard (2012), Martin (1995) e Viertler (2002).

As coletas botânicas ocorreram nas roças, por meio de trilhas guiadas, que conforme estabelece Brondízio e Neves (1996), participantes da pesquisa (guias) com domínio sobre as espécies vegetais locais, separadamente percorrem as unidades de paisagem indicando as plantas conhecidas, as quais são registradas pelo responsável pela realização da pesquisa. Foram realizadas oito incursões orientadas por cinco guias locais em diferentes épocas de cultivo das roças.

O material testemunha da flora foi armazenado no HPAN - Herbário do Pantanal "Valli Joana Pott", na Universidade do Estado de Mato Grosso, Campus de Cáceres.

Este estudo foi executado com aprovação do Comitê de Ética em Pesquisa - CEP - UNEMAT, Universidade do Estado de Mato Grosso, parecer n 1.404 .395 e assinaturas do Termo de Consentimento Livre e Esclarecido (TCLE) pelos participantes da pesquisa. Foi assegurado o sigilo de suas identidades.

\section{Resultados e Discussão}


Principais unidades produtivas locais.

Os espaços de plantio e manejo de espécies de cultivo agrícola presentes nas unidades rurais de Saloba Grande e Novo Oriente são denominados localmente por roças, chácaras / chacrinhas e quintais (Figura 2). Nestes espaços são cultivadas plantas alimentares que promovem a subsistência familiar dos moradores. A produção excedente é comercializada entre as famílias locais e no município de Porto Estrela.

Figura 2 - A) Roça com presença de espécies nativas de vegetação natural mantidas no sistema, na comunidade rural Novo Oriente, Porto Estrela, 2016; B) Chácara / chacrinha com policultivo de Carica papaya L. (mamão), Saccharum officinarum L. (cana), Curcubita pepo L. (abóbora) e Allium fistulosum L. (cebolinha) em unidade rural da comunidade Novo Oriente, MT, Porto Estrela, 2016; C) Quintal com produção de feijão, após cultivo de milho / rotação de cultura, em residência da comunidade rural Saloba Grande, MT, Porto Estrela, 2016.
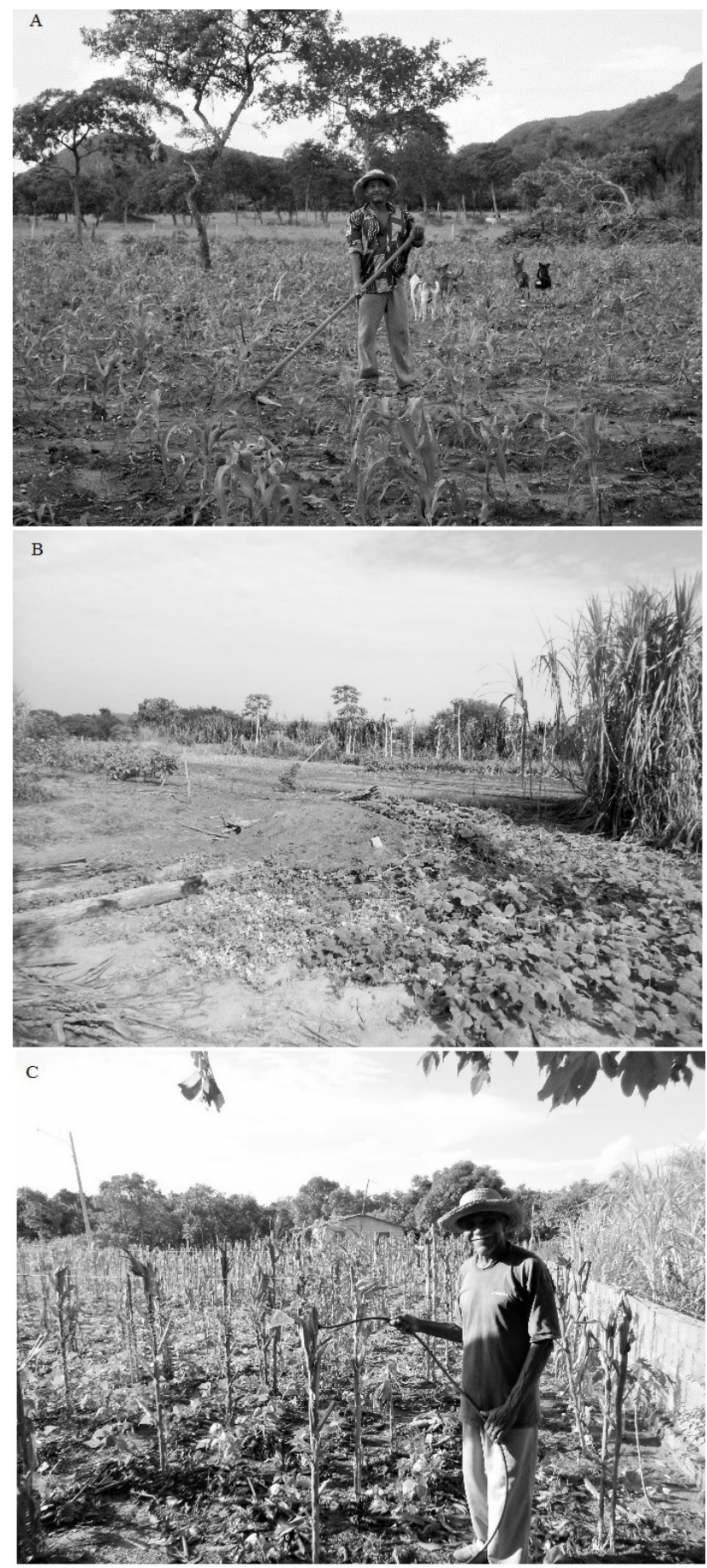
As roças

As roças apresentam extensão territorial que variam de 1.605,61 $\mathrm{m}^{2}$ à $6.788,30 \mathrm{~m}^{2}$. Foram estudadas quatro roças (todo o universo da pesquisa) nas quais são cultivadas as espécies Manihot esculenta Crantz (mandioca), Zea mays L. (milho), feijão Musa paradisiaca L. (banana), Citrullus lanatus (Thunb.) Matsum. \& Nakai (melancia), Curcubita pepo L. (abóbora), Abelmoschus esculentus (L.) Moench (quiabo), Cucumis anguria L. (maxixe) e Cucumis sativus L. (pepino), nos sistemas de policultura e rotação de espécies agrícolas em cultivo único. Neste último registrou-se a banana como única espécie alimentar cultivada, porém com a manutenção de espécies nativas preservadas.

As justificativas atribuídas para a conservação de espécies nativas no sistema estão relacionadas as suas categorias de uso. Neste sentido as plantas preservadas são preferencialmente aquelas com potencial medicinal, alimentar ou madeireiro. Dentre estas foram encontradas Acrocomia aculeata (Jacq.) Lodd. ex Mart. (bocaiúva), Attalea speciosa Mart. ex Spreng. (babaçu), Caryocar brasiliense A. St - Hil. (pequi), Cecropia pachystacbya Trécul (embaúba), Cnidoscolus urens (L) Arthur (cançançã), Curatella americana L. (lixeira), Dipteryx alata Vogel (cumbaru), Ertela trifolia (L.) Kuntze (manacá), Euphorbiapotentilioides Boiss (sete-sangria), Hyptis suaveolens Poit. (tapera-velha), Luehea paniculata Mart \&Zucc (açoita-cavalo), Phyllanthus orbiculatus Rich. (quebra-pedra) e Vochysia haenkeana Mart. (cambará / cambará amarelo) (tabela 1).

Para a categoria de uso medicinal Mangifera indica L. (manga) se destaca com afecções mais citadas relacionadas aos sintomas que acometem o sistema respiratório, tais como gripe, tosse e dores em geral. A parte utilizada mais utilizada é a folha sob a forma de chá. No entanto, a casca de $M$. indica também foi citada como importante recurso para o tratamento de viroses como dengue e zika.

O Babaçu foi indicado para desnutrição de crianças. Recomenda-se tirar a polpa do fruto maduro, secar, triturar e adicionar água ou leite em pó

Foram encontradas 22 espécies vegetais nas roças atribuídas à 18 famílias botânicas que incluem plantas cultivadas ou espontâneas. Dentre estas últimas destacam-se espécies comuns da vegetação natural como $A$. speciosa, C. brasiliense, C. Americana, C. urens, E. potentilioides, D. alata, E. trifolia, L. paniculata, P. orbiculatus, C. pachystachya e $V$. haenkeana.

As que apresentaram maiores indicações de uso foram Attalea speciosa Mart. Ex Spreng. (Babaçú) (6) e Mangifera indica L. (Manga) (5). Estas foram constatadas em todas as unidades de paisagens / cultivos locais, encontrando-se espacialmente distribuídas nos quintais, chácaras, roças, pastagens e na vegetação natural.

Técnicas tradicionais de construção revelam-se presentes. $M$. indica e $A$. speciosa fazem parte de variadas edificações. A população local detém a técnica correta para se trançar a palha utilizada na cobertura das casas.

Os ensinamentos relacionados a essa prática são repassados geração em geração, dos genitores idosos para seus filhos. Segundo relato oral de um jovem morador de Saloba Grande a palha de babaçu deve ser retirada durante a lua minguante, pois garante maior durabilidade a cobertura, e após três dias a lua cheia caso contrário aparecem brocas (insetos que se alimentam da palha).

Essa forte presença reflete a importância destes recursos no cotidiano da população local manifestada pela diversidade de usos atribuídos a tais espécies.

Dentre as quatro famílias participantes duas realizam o autoconsumo dos produtos cultivados e duas comercializam a produção excedente. A responsabilidade do manejo desses espaços é atribuída aos homens. 
Esporadicamente as esposas podem auxiliar seus maridos na manutenção desses espaços mas suas atividades são vistas como "ajuda".

Tabela 1 - Lista de plantas encontradas em roças e outras unidades produtivas das comunidades rurais Saloba Grande e Novo Oriente, Porto Estrela MT, Brasil. Legenda: $\mathrm{N}^{\circ}$ de Cit/sp: Número de citações/espécie. Ah: alimentação humana; Aa: alimentação animal; Ar: artesanal; Co: construção; Ma: madeireira; Me: medicinal / remédio; So: sombra. QT: quintal; CH: chácara; RÇ: roça; PT:pastagem; VN: vegetação natural.

\begin{tabular}{|c|c|c|c|c|}
\hline Família botânica / Espécie & $\begin{array}{l}\text { Denominação } \\
\text { Local }\end{array}$ & $\begin{array}{l}\text { Categorias de } \\
\text { uso }\end{array}$ & $\begin{array}{l}\mathrm{N}^{\circ} \text { de } \\
\text { Cit/sp. }\end{array}$ & $\begin{array}{c}\text { Unid. de } \\
\text { paisagem / cultivo } \\
\text { encontrada }\end{array}$ \\
\hline \multicolumn{5}{|l|}{ Anacardiaceae } \\
\hline Mangifera indica L. & Manga & $\begin{array}{c}\text { Ah, Aa, Me, Ma, } \\
\text { Co. So }\end{array}$ & 19 & QT, RÇ, CH, PT, VN \\
\hline \multicolumn{5}{|l|}{ Araceae } \\
\hline Colocasia esculenta (L.) Schott & Cará & $\mathrm{Ah}, \mathrm{Aa}$ & 9 & $\mathrm{QT}, \mathrm{RC}, \mathrm{CH}$ \\
\hline \multicolumn{5}{|l|}{ Bromeliaceae } \\
\hline Ananas comosus (L.) Merril & Abacaxi & $\mathrm{Ah}$ & 5 & QT, RÇ \\
\hline $\begin{array}{l}\text { Arecaceae } \\
\text { Acrocomia aculeata (Jacq.) Lodd. ex } \\
\text { Mart. }\end{array}$ & $\begin{array}{l}\text { Bocaiúva, Ba- } \\
\text { caiúva }\end{array}$ & $\mathrm{Ah}, \mathrm{Me}$ & 7 & QT, RÇ, VN \\
\hline Attalea speciosa Mart. ex Spreng. & Babaçu, aguaçú & $\begin{array}{c}\text { Ah, Aa, Me, Co, } \\
\text { Ar }\end{array}$ & 13 & QT, RÇ, CH, PT, VN \\
\hline $\begin{array}{l}\text { Caryocaraceae } \\
\text { Caryocar brasiliense A. St - Hil. } \\
\text { Curcubitaceae }\end{array}$ & Pequi, piqui & 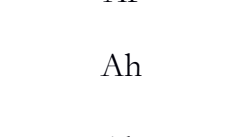 & 10 & QT, CH, RÇ, PT, VN \\
\hline Citrullus lanatus (Thunb.) & Melancia & $\mathrm{Ah}$ & 2 & $\mathrm{CH}, \mathrm{RC}$ \\
\hline Curcubita pepo L. & Abóbora & Ah & 5 & QT, CH, RÇ \\
\hline \multicolumn{5}{|l|}{ Urticaceae } \\
\hline \multicolumn{5}{|l|}{ Dilleniaceae } \\
\hline \multicolumn{5}{|l|}{ Dioscoraeceae } \\
\hline \multicolumn{4}{|l|}{ Euphorbiaceae } & QT, RÇ \\
\hline Cnidoscolus urens $(\mathrm{L})$ Arthur & Cançançã & $\mathrm{Me}$ & 2 & $\mathrm{RÇ,} \mathrm{VN}$ \\
\hline Euphorbia potentilioides Boiss.v & Sete-sangria & $\mathrm{Me}$ & 2 & $\mathrm{RÇ}, \mathrm{VN}$ \\
\hline Manihot esculenta Crantz & Mandioca & $\mathrm{Ah}, \mathrm{Aa}, \mathrm{Me}$ & 18 & $\mathrm{QT}, \mathrm{CH}, \mathrm{RC}$ \\
\hline \multicolumn{5}{|l|}{ Fabaceae } \\
\hline $\begin{array}{l}\text { Dipteryx alata Vogel } \\
\text { Lamiaceae }\end{array}$ & Cumbarú & $\mathrm{Ah}, \mathrm{Ma}, \mathrm{Me}$ & 21 & QT, CH, RÇ, PT, VN \\
\hline $\begin{array}{l}\text { Hyptis suaveolens Poit. } \\
\text { Rutaceae }\end{array}$ & Tapera-velha & $\mathrm{Me}$ & 3 & QT, RÇ \\
\hline $\begin{array}{l}\text { Ertela trifolia (L.) Kuntze } \\
\text { Malvaceae }\end{array}$ & Manacá & $\mathrm{Me}$ & 8 & $\mathrm{RÇ,} \mathrm{VN}$ \\
\hline $\begin{array}{l}\text { Luehea paniculata Mart \& Zucc } \\
\text { Phyllanthaceae }\end{array}$ & Açoita-cavalo & $\mathrm{Me}, \mathrm{Co}$ & 5 & $\mathrm{RC}, \mathrm{VN}$ \\
\hline $\begin{array}{l}\text { Phyllanthus orbiculatus Rich. } \\
\text { Vochysiaceae }\end{array}$ & Quebra-pedra & $\mathrm{Me}$ & 3 & QT, RÇ, VN \\
\hline $\begin{array}{l}\text { Vochysia haenkeana Mart. } \\
\text { Poaceae }\end{array}$ & $\begin{array}{l}\text { Cambará, Cam- } \\
\text { bará-amarelo }\end{array}$ & $\mathrm{Ma}, \mathrm{Me}$ & 5 & $\mathrm{RC}_{3}, \mathrm{VN}$ \\
\hline $\begin{array}{l}\text { Zea mays } \mathrm{L} . \\
\text { Musaceae }\end{array}$ & Milho & $\mathrm{Ah}, \mathrm{Aa}$ & 4 & QT, RÇ \\
\hline Musa paradisiaca L. & Banana & $\mathrm{Ah}$ & 20 & QT, $\mathrm{CH}, \mathrm{RC}$ \\
\hline
\end{tabular}

No que se refere à origem do material para o plantio, os quatro agricultores participantes (100\%) afirmaram realizar troca de sementes com vizinhos e familiares. Dentre estes, dois também destacam que as compram. As justificativas apontadas para a realização das trocas de propágulos vegetais são: oportunidade de compartilhar alimentos com familiares e amigos e conservação das espécies vegetais, principalmente de M. esculenta (mandioca) 
e Z. mays (milho). Segundo os agricultores esta prática promove a diferenciação das espécies, e que, pelo fato de não encontrá-las disponíveis no comércio é necessário conservá-las. Neste sentido, mandioca e milho são cultivados nas roças e quintais por meio da troca de propágulos entre parentes e amigos / vizinhos.

Lyra et al. (2011) registraram que os agricultores de Jequié-BA, conservam suas sementes de feijão, milho e quiabo em garrafas "pets", armazenando parte delas para a próxima safra, sendo uma parte para venda e outra para troca com outros agricultores da região, mostrando a provável influência dos agricultores na dispersão da variabilidade genética.

Ao longo dos séculos as sementes vêm sendo manejadas por agricultores de subsistência. Melhorar e difundir as sementes da diversidade local são práticas importantes que possuem o mérito de resgatar conhecimentos, tradições, e hábitos alimentares tradicionais, contribuindo para o reconhecimento e a valorização dos saberes, da cultura e da identidade camponesa (Londres, 2014).

No que se refere à escolha das áreas em que as roças serão formadas, considera-se a distância entre a unidade de cultivo e a residência, coloração / fertilidade do solo, declividade e o tipo de formação vegetacional local. Preferencialmente as roças devem estabelecer-se em regiões planas em um ponto mediano, nem muito distante e nem muito próximas às casas.

O solo precisa apresentar coloração escura, pois é considerado pelos agricultores como o mais fértil. Em unidades rurais que apresentam atividade de pecuária, a pastagem é desmanchada para o manejo das roças. Esta é uma prática utilizada com o objetivo de aproveitar áreas antropizadas sem que seja necessário desmatar a vegetação nativa.

Em locais que necessitam serem desmatados, as áreas priorizadas são aquelas que apresentam alguns tipos específicos de espécies vegetais. Segundo os agricultores, os locais ideais são aqueles que apresentem bacuri (Attalea phalerata Mart. Ex Spreng), denominados localmente de "terra de bacuri" ou que apresentem outras espécies arbóreas de grande porte como jatobá (Hymenaea courbaril L.) e ipê (Handroanthus impetiginosus (Mart. ex DC.) Mattos). Áreas que apresentam essas características não precisam ser submetidas à correção de solo com utilização de calcário. Neste caso é necessário apenas "reforçar a terra" utilizando-se adubos químicos.

Os critérios adotados por agricultores da comunidade Santana, região da morraria de Cáceres - MT, para o cultivo das roças também são associados à presença de bacuri Attalea phalerata Mart. Ex Spreng, Anadenanthera sp. (angico), Dipteryx alata Vogel cumbaru e Cedrela fissilisVell. (cedro) (Mendes 2005).

O manejo da roça é iniciado com a abertura da área, o solo é gradeado e o plantio é iniciado manualmente, com auxílio de plantadeira denominada matraca. Os participantes declararam que o uso do fogo deixou de fazer parte das práticas agrícolas locais, sendo substituída pelo método de gradeamento.

Segundo os agricultores são necessários cuidados especiais no manejo da roça que acompanham a cosmologia lunar. As luas crescente e minguante são consideradas ideais para plantar. Os participantes desta pesquisa revelaram que para atingir uma produção precoce o plantio da mandioca deve ser realizado durante a lua minguante, enquanto que para adquirir maior durabilidade ao produto é necessário que o plantio ocorra na fase nova.

O plantio de milho e feijão deve ocorrer após a lua Nova ou até três dias após a fase crescente, enquanto que a colheita deve ser realizada durante a minguante, prática que evita o aparecimento de carunchos.

Neste sentido os agricultores definem a influência lunar sobre o desenvolvimento da planta de acordo com o crescimento da parte em que se concentra o interesse da produção. Vegetais em que a parte que gera o produto 
de interesse é a raiz, cujo crescimento é subterrâneo como a mandioca e o cará devem ser plantados durante a lua minguante. As plantas de crescimento aéreo que o produto de interesse dos agricultores são frutos e sementes, como o milho e o feijão, o plantio é recomendado durante a fase de lua nova.

Ao descrever e analisar o uso e manejo dos recursos vegetais nas comunidades Nossa Senhora da Guia e Santana, região da morraria em Cáceres, MT, Oliveira (2006) também demonstrou que as categorizações das plantas que recebem influência lunar no seu cultivo são: plantas de raiz ou plantas embaixo da terra (lua minguante), plantas em cima da terra (lua nova).

No assentamento Laranjeiras I, em Cáceres, MT os agricultores acreditam que a lua minguante é a fase ideal para o cultivo de plantas tuberosas e oleaginosas, pois impedem a formação de carunchos, enquanto a lua nova é adequada para o cultivo de arroz e de verduras (Santos, 2015). As recomendações de plantio e colheita que seguem as fases lunares são comuns na região e se mantêm vivas entre os agricultores de pequenas propriedades.

No que se refere a utilização de insumos, duas famílias que comercializam a produção afirmaram utilizar defensivos agrícolas, fertilizantes e adubos químicos, enquanto que duas utilizam os produtos para o autoconsumo afirmam utilizar apenas adubos orgânicos nas roças.

Todos os participantes afirmaram que o conhecimento sobre o manejo das roças foi adquirido observando as práticas agrícolas de vizinhos e familiares especialmente por meio dos ensinamentos recebidos de seus pais ou padrastos. Esse acervo de conhecimentos atualmente é repassado aos filhos e netos que ainda permanecem nas comunidades. Os agricultores mais idosos que já não possuem filhos no convívio familiar, transferem o conhecimento a amigos ou vizinhos. Neste sentido sugere-se a o conhecimento sobre práticas agrícolas tradicionais estão sendo repassados horizontalmente e verticalmente nessas comunidades, essencialmente aos homens.

Sobre a importância dessas unidades de cultivo, os participantes apontaram que as roças significam fonte de renda e alimento. Toda a produção é aproveitada pelas famílias. Restos dos produtos agrícolas não aptos ao consumo humano como bagaço de cana-de-açúcar e palha de milho são oferecidos à criação animal ou utilizados como adubo orgânico.

Para as famílias a roça é sinônimo de boas lembranças devido à relação de convivência e união entre familiares e amigos residentes de comunidades vizinhas, antes manifestadas por meio do manejo com cooperação mútua entre os moradores locais. Essas práticas eram chamadas de mutirões e atualmente deixaram de fazer parte do cotidiano das famílias. Os chefes de família (pais) relataram que o sustento econômico e alimentar de seus filhos, desde a infância, foi garantido com a produção advinda das roças.

Dentre as principais dificuldades apontadas pelos agricultores para a continuidade dessa prática tradicional estão: aumento de pragas e predadores nas lavouras, redução de força de trabalho devido à idade avançada, migração dos jovens / filhos para os centros urbanos, proibição do uso do fogo no manejo da terra, mecanização deficitária e cara e aumento das áreas de pastagem em consequência da pressão exercida pelos grandes fazendeiros que se estabeleceram na região desde o final do século passado. Por meio dos relatos que se seguem é possível perceber as dificuldades encontradas pelos moradores para manutenção da prática de manejo de roças e suas percepções associadas à transformação do ambiente fator que contribui para a redução de áreas cultiváveis:

Então, primeiro tem que roçá né, queimá num pode, aí é só mato, e nóis num pode mexê com a máquina. E otro que.... tudo mundo (sitiantes locais e migrantes) tá viranu fazendero, sitiante limpa tudo pá criá gado.” (C. F. Novo Oriente). 
Segundo Forline (2007) geralmente as áreas alteradas são percebidas primeiramente por moradores locais ou que residem próximos a estas, que, por fazerem e serem parte deste ambiente, reconhecem facilmente as ações antrópicas que provocam as transformações na paisagem.

A introdução de espécies desconhecidas, como a braquiária, por exemplo, substitui capins já adaptados às pragas locais e promove o fortalecimento de pragas desconhecidas pela população local. O espremimento desses povos, gerados por sistemas de monocultura, pecuária, e consequentemente o aumento de terras desmatadas e degradadas interferem no sistema produtivo tradicional destas comunidades e enfraquecem seu modelo de reprodução social (Almeida 2005).

Ações antrópicas geradas principalmente por meio da intensificação da pecuária e redução de vegetação nativa para conversão de pastagens, foram fatores que aceleraram as transformações do ambiente e consequente redução de alimento no meio natural e a invasão dos animais nativos. No entanto as justificativas atribuídas pelos participantes desta pesquisa para a invasão de animais silvestres nas roças referem-se a diminuição dessas unidades de cultivo que reduzem a oferta de alimento para os animais como descrito nos seguintes relatos.

Aqui era só roça. Tudo mundo, a família tudo... era mulher, criançada, criava na roça... tuda vida minha profissão foi roça. Agora num tem mais. Com a história que tudo foi ficano difícil. Os novo começô só estuda né... os véio foi ficano cansado... num guenta mais né! Mas minha vida memo foi só roça, atéee quando eu guentei. Aqui cabo memo, tem bitcho demáx (muitos animais). As roça foi ficano poco, aí cê pranta uma rocinha, só os bitcho come tudo. Antigamente tinha bitcho, mas a roça era bastante, então ele comia de um... de otro... então dividia os pridjuízo né! De vez em quando comia um (bicho), né! (risos). Agora num pode! Na verdade as roça diminuiu, então parece que os bitcho aumento demáx. Um pranta uma rocinha aqui, outra alí... mas um num pranta, otros já num pranta... aí os bitcho chega lá e come tudinho. (A. I, Saloba Grande).

Ocê sabe que o que pranta lá na roça agora, aquele tatu num dexa, come tudo, revira igual porco. Num adianta prantá mais, que tem muito. Sabe o que? Agora eles num acharu mais mandioca lá, porque a gente prantava mandioquinha por lá, eles ficava comenu a mandioca. Agora num acharu mais e foro no cará. Nóis fumo lá ante onte rancá cará, tá tudo rivirado. Agora nem cará pode tê mais lá... nada! Agora tem que prantá tudo no quintal, si quisé.” (M.H, Novo Oriente).

Em decorrência da escassez do meio natural onde antigamente a alimentação se dava em equilíbrio entre produção no ambiente natural e consumidores próprios do ambiente o agricultor é motivado à buscar alternativas que salvem sua produção alimentar. Neste caso o quintal torna-se reservatório de proteção e conservação das espécies vegetais que são submetidas à ação de animais que invadem as roças em busca de alimento.

Neste sentido, Amorozo (2002) destaca que para o agricultor de subsistência, tal alternativa pode se constituir em uma estratégia de conservação e manutenção da diversidade por possibilitar lidar com fatores imprevisíveis que possam colocar a produção em risco.

As dificuldades relatadas pelos participantes como o aumento de pragas e predadores nos sistemas de cultivo, conversão de áreas cultiváveis em pastagens, diminuição de jovens e aumento da população idosa nas comunidades são fatores locais que contribuem para a redução aparente da prática de manejo de roças. Rodrigues et al. (2015), identificou uma diminuição dessas práticas tradicionais na região do Taquaral comunidade rural Nossa Senhora da Guia em Cáceres, MT, localidade distante $70 \mathrm{~km}$ de Saloba Grande e Novo Oriente. Dentre as 13 famílias residentes em Nossa Senhora da Guia, somente cinco (38,41\%), ainda mantêm roças tradicionais em pequena escala de produção.

Segundo os moradores antigos de Saloba Grande e Novo Oriente o gradativo abandono desta prática na região da morraria ocorreu devido a fatores econômicos globais que afetam a produção local como a pressão causada pelos sistemas de monocultura em grande escala, que representam forte concorrência no mercado, e aos 
altos custos de produção como pode ser verificado no seguinte relato:

Aí foi acabano as roça... aí foi criano as firma que produz bastante né... então aí a produção fica baratinho de uma vez... aí se o pobre lavradô pequeno produz, fica difícil até pá vendê. E aí foi entrano as difirculdade e foi acabano... fazeno uma rocinha assim só pá comê, até que foi acabano... Hoje quando cê qué comê, vai no mercado! (A.I. Saloba Grande).

É possível notar, por meio do seguinte relato de um morador, o sentimento de alienação ao mercado capitalista, em que o mesmo consegue apontar somente essa alternativa para o consumo alimentar das famílias.

É... se num é os gaúcho, porque os gaúcho são ganante pá tocá a vida, né... tocá lavoras grandes né... como aqui memo no norte, aí tem gaúcho que entora tudo que tem pá tocá lavora, tem grandes maquinário e eles arrenda grandes terra né. Tem avião, tem tudo pá fazê serviço. Se deus u livre de chegá de pará de prantá, aí o povo vai passá fome. Ocê pode andá daqui no Porto Estrela que cê num acha uma espiga de milho, pra cá é mesma coisa. Tudo tem que comprá no mercado. Ou então vai lá no Norte... cê vê... um saco de milho aqui tá valeno 50 reais e lá no Norte tá valeno 12, 13 reais, defereente... mai porque eles pranta. Lá eles pranta é muito lavora... 200, 300 a 500 arquere de... só de milho! Aqui foi cabano porque ficô mais difícil. Mais aí depende de cê pagá um frete né... pá i lá buscá. Aí já torna ficá caro. Daí já é mais preferido comprá no mercado. (M. D. Novo Oriente).

Constatou-se que a autoestima do agricultor, por ser um pequeno agricultor, e de sua própria prática de cultivo está extremamente fragilizada. O agricultor assimilou a supervalorização da monocultura do migrante sulista, especialmente em Mato Grosso como a alternativa capaz de resolver os problemas de suprimento de alimentos e demais produtos consumidos.

Sobre esse aspecto Diegues (2004) enfatiza que atualmente no país, a maioria das comunidades rurais tradicionais sofrem os efeitos da dependência da concepção social capitalista.

Os pequenos agricultores possuem maior ou menor dependência desse sistema e quando isso ocorre, há uma consequente desorganização no modo como as práticas de agricultura de pequena escala se apresentam na produção mercantil. No que se refere a esse aspecto, Pasa (2010) afirma que elementos externos esmagadores como o capitalismo, aos poucos, tendem a dissipar a riqueza de experiências construída pelo homem por meio do elo simbiótico entre meio ambiente e tudo o rodeia.

Quando as situações de vida dos agricultores passam por mudanças, devido à introdução de novos padrões sociais e produtivos, o conhecimento compartilhado também pode se enfraquecer em consequência da perca dos valores relacionados à agrobiodiversidade. Esses fatores podem comprometer perspectivas futuras de conservação on farm (Amorozo 2013).

A continuidade dessa prática ainda se mantém pelo sentimento que se tem sobre o manejo das roças e os conhecimentos passados pelos familiares. Este fato pode ser percebido por meio das manifestações de sentimentos aliados a essa prática, como se segue na seguinte fala: Mas enquanto Deus me dé vida, que eu tive aguentano... uma rocinha... Eu gosto da roça, pra mim é uma alegria!” (C. F. Novo Oriente).

Neste sentido este agricultor apontou que já não possui filhos para ajudá-lo no manejo das roças e mesmo com todas as dificuldades para a manutenção destas práticas, seu desejo é continuar perpetuando essa tradição aprendida e vivenciada ao longo de sua vida. Para Santos et al., (2016), muitas vezes, a persistências em perpetuar práticas familiares promove a manutenção do modo de vida tradicional e representa uma estratégia de reprodução física e simbólica de sua cultura.

Ações integradas entre a Estação Ecológica da Serra das Araras e moradores de seu entorno devem se constituir em estratégias que visem melhorar a qualidade de vida das populações residentes em Saloba Grande e Novo Oriente e o incentivo às atividades econômicas locais que integrem conservação, educação ambiental e 
fortalecimento das culturas e as tradições locais.

\section{CoNSIDERAÇÕES FINAIS}

O manejo de roças está deixando de fazer parte das práticas tradicionais das famílias de Saloba Grande e Novo Oriente. Neste sentido as chácaras representam uma alternativa para o cultivo de plantas agrícolas que geralmente são cultivadas nas roças.

Dentre as justificativas para o gradativo abandono da prática de manejo de roças estão: força física limitada, especialmente dos agricultores, que se encontram em idade avançada, redução de mão de obra familiar em decorrência da migração dos jovens para os centros urbanos; entraves com o IBAMA devido à proibição do uso do fogo e desmate de vegetação nativa para formação de novas áreas de cultivo; aumento de predadores e pragas agrícolas e altos custos de produção retorno financeiro não compensatório devido a competitividade de mercado diante da produção agrícola em grande escala em ascensão na região.

A definição e implementação de políticas públicas de fomento às práticas agrícolas tradicionais ainda vivas nas comunidades podem auxiliar as famílias a permanecer no local, manter suas tradições e costumes em condições de se inserir e manter-se no mercado.

\section{Agradecimentos}

Ao povo das comunidades rurais Saloba Grande, Novo Oriente pelos ensinamentos e hospitalidade durante os trabalhos de campo. Aos funcionários do ICMBio / Estação Ecológica da Serra das Araras. À Universidade do Estado de Mato Grosso - UNEMAT / Programa de Pós Graduação em Ciências Ambientais - PRPPG. À Secretaria de Estado de Educação de Mato Grosso / SEDUC - MT pela concessão de licença para qualificação profissional.

\section{REFERÊNCIAS}

Aguiar, MVA. 2007. El aporte del conocimiento local para eldesarrollo rural: un estudio de caso sobre el uso de la biodiversidade en dos comunidades campesinas tradicional es del estado de Mato Grosso - Brasil. Tese de Doutorado em Agroecologia, Sociologia y Desarrollo Sostenible - Instituto de Sociología y Estudios Campesinos, Universidad de Córdoba. 730p.

Alexiades, MN and Sheldon, JW. 1996. Selected guidelines for ethnobotanical research: a field manual. New York Botanical Garden. 305p.

Almeida, RA. de. 2005. Do Tempo da Terra Comum ao Espremimento: Estudo sobre a lógica e o saber camponês na Baixada Cuiabana. Dissertação de mestrado. Instituto de Ciências Sociais. Programa de PósGraduação em Antropologia Social. Universidade de Brasília - UNB. Brasília. 211p.

Amorozo, MC. de M. 2002. Agricultura tradicional, espaços de resistência e o prazer de plantar. p.123-131. In: U. 
P. de Albuquerque; A. G. C. Alves; A. C. B. L. e Silva e V. A. Da Silva (Orgs.). Atualidades em Etnobiologia e Etnoecologia. Recife: Sociedade Brasileira de Etnobiologia e Etnoecologia. Recife, PE, Ed. SBEE. 151p. Amorozo, MDM. 2013. Sistemas agrícolas de pequena escala e a manutenção da agrobiodiversidadeuma revisão e contribuições. Rio Claro, SP: Edição do autor. 120p.

Bernard, HR. 2012. Social researchmethods: Qualitativeandquantitative approaches.Sage. 803p.

Brondízio, ES.; Neves, WA. Populações caboclas no estuário do Amazonas: A percepção do ambiente natural. ARAÚJO, MC de (ed.) Uma estratégia latino-americana para a Amazônia. Brasília: Ministério do Meio Ambiente dos Recursos Hídricos e da Amazônia Legal, São Paulo: Memorial, p. 167-181, 1996.

Diegues, AC. 2004. O mito moderno da natureza intocada: populações tradicionais em unidades de conservação. NUPAUB-USP, São Paulo. 170p.

IBGE - Instituto Brasileiro de Geografia e estatística. Cidades. Disponível em: < http://cidades.ibge.gov.br/

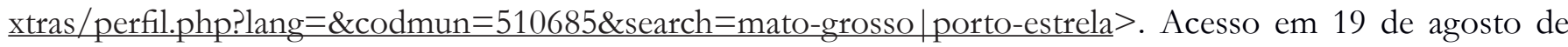
2016.

Forline, L. 2007. Áreas antrópicas: de onde vieram e para quem funcionam? In: Albuquerque, UP, Alves, AG e Araujo TAS (Orgs.) Povos e paisagens: etnobiologia, etnoecologia e biodiversidade no Brasil. Recife: NUPEEA/UFRPE. 148p.

Galluzzi, G, Eyzaguirre, P and Negri, V. 2010. Home gardens: neglectedhotspotsofagro-biodiversityand cultural diversity. BiodiversityandConservation, 19(13), 3635-3654.

Grisa, C. 2007. Para além da alimentação: papéis e significados da produção para autoconsumo na agricultura familiar. Revista Extensão Rural, 14(1), 13-54.

Goodman, LA. 1961. "Snowball Sampling.” Annals of Mathematical Statistics 32(1):148-170.

Londres, F. 2014. Sementes da diversidade: a identidade e o futuro da agricultura familiar. Agriculturas. (11) 1, 04-11.

Lyra, DH, Sampaio, L. S, de Almeida Pereira, D e Amaral, CLF. 2011. Conservação onfarm da agrobiodiversidade de sítios familiares em Jequié, Bahia, Brasil. Revista Ceres, 58(1), 69-76.

Martin, GJ. 1995. Ethnobotany: a methods manual (Vol. 1). Earthscan. 263p.

Mendes, RR. 2005. Manejo e uso da vegetação nativa por agricultores tradicionais da comunidade Santana, região da Morraria, Cáceres-MT. Dissertação de Mestrado em Agricultura Tropical. Universidade Federal de Mato Grosso, Faculdade de Agronomia e Medicina Veterinária. Cuiabá. 103p.

MMA. 2015. Plano de Manejo: Estação Ecológica Serra das Araras. Instituto Chico Mendes de Conservação da Biodiversidade - ICMBio, Brasília.

Oliveira, RC de. 2006. Uso e manejo de recursos nos arredores das residências de camponeses: estudo de 
caso na região de Morraria, Cáceres, MT. Dissertação de Mestrado em Agricultura Tropical. Universidade Federal de Mato Grosso, Faculdade de Agronomia e Medicina Veterinária. Cuiabá. 166 p.

Pasa, MC, Ávila G. de. 2010. Ribeirinhos e recursos vegetais: a etnobotânica em Rondonópolis, Mato Grosso, Brasil. Interações. Campo Grande, (11)2. 195-204.

Posey, DA. 1986. Manejo da floresta secundária, capoeiras, campos e cerrados (Kayapó). In: Suma etnológica brasileira: Etnobiologia, Petrópolis: Vozes. Edição atualizada do Handbookof South American Indians. 1, Petrópolis, RJ.

Ribeiro, JF; Walter Fiho, B. M. T. 2008. As Principais Fitofisionomias do Bioma Cerrado. In: Cerrado: ecologia e flora. Embrapa Cerrados, Brasília - DF: Embrapa Informação Tecnológica.

Rigonato, VD e Almeida, M. 2004. Cerrado: a fitofisionomia e a inter-relação com as populações tradicionais. Departamento de Geociências da Universidade Estadual de Montes Claros - UNIMONTES, 2(1), 39-53.

Rodrigues, LC, Neves, RJ, Carniello, MA, Santos, JSV dos. 2015. Caracterização sociocultural da região do Taquaral: Comunidade Nossa Senhora da Guia, Cáceres, MT, Brasil. Revista de Geografia (UFPE).32(3), 87-104.

Santos, TM dos. 2015. Estudo etnobotânico nas propriedades estabelecidas na região de nascentes de água do assentamento Laranjeira I, Cáceres, Mato Grosso. Dissertação de mestrado em Ciências Ambientais. Universidade do Estado de Mato Grosso, UNEMAT, Cáceres. 163 p.

Santos, TA, Carniello, MA e Barros, FB. 2016. Práticas Agroecológicas e Conhecimentos Tradicionais na Chácara Santo Antônio, Cáceres-MT, Brasil. Revista Gaia Scientia. 10(4).

Valadão, RM. 2012. Birdsofthe Estação Ecológica Serra das Araras, Mato Grosso, Brazil. Biota Neotropica, 12(3), 263-281.

Viertler, RB. 2002. Métodos Antropológicos como Ferramenta para Estudos em Etnobiologiae Etnoecologia. p.11-29. In: Amorozo, MCM de, Ming, LC, Silva, SM. P da. Métodos de Coleta e Análise de dados em Etnobiologia, Etnoecologia e Disciplinas Correlatas. Seminário de Etnobiologia e Etnoecologia no Sudeste. Rio Claro: Coordenadoria da Área de Ciências Biológicas - Gabinete do Reitor - UNESP/CNPq. 204p. 